\title{
Alimentação segura em creche filantrópica no município de Viçosa - MG
}

\author{
Maria Abreu Gott Cunha ${ }^{I}$, Regina Célia Rodrigues de Miranda Milagres², \\ Jessilene de Freitas Lopes ${ }^{3}$, Júlia Rodrigues de Oliveira ${ }^{4}$ Eliana Carla \\ Gomes de Souza ${ }^{5}$, Ceres Mattos Della Lucia ${ }^{6}$
}

\begin{abstract}
Resumo: Pré-escolares carecem de maior atenção no controle higiênico, considerando a vulnerabilidade do seu sistema imunológico. Objetivou-se relatar as ações extensionistas realizadas em serviço de alimentação de uma creche filantrópica de Viçosa (MG) em relação às Boas Práticas de Fabricação (BPF). Foram realizadas as atividades: aplicação de Listas de Verificação das BPF antes e após intervenções; implementação de plano de ação para melhorias estruturais; oficinas sobre higiene; elaboração de Manual de Boas Práticas (MBP) e Procedimentos Operacionais Padronizados (POP). Após as intervenções houve melhorias expressivas nas BPF com aumento de quase $20 \%$ de atendimento aos itens da legislação. Medidas corretivas estruturais, capacitações, acesso ao MBP e aos POP propiciaram melhorias nas práticas de higiene dos manipuladores. Conclui-se que as ações do projeto tornaram possível adequar a instituição às BPF, promoveram a interação ensino, pesquisa e extensão, já que o aprendizado acadêmico pode ser trocado com a comunidade.
\end{abstract}

Palavras-chave: Boas práticas de fabricação. Manipuladores de alimentos. Pré-escolares.

Área Temática: Saúde. Educação.

\section{Safe feeding in philanthropic daycare in the municipality of Viçosa - MG}

\begin{abstract}
Pre-school children need greater attention in hygiene control, considering the vulnerability of their immune system. Our aim was to report the development of extension actions used in the food service of a philanthropic daycare from Viçosa (MG), Brazil, in relation to Good Manufacturing Practices (GMP). Two GMP Checklists were applied before and after interventions; implemented action plan for structural improvements; hygiene workshops were held and a Good Practice Manual (MBP) and Standardized Operating Procedures (SOP) were prepared. After the interventions there were improvements in GMP with an increase of almost $20 \%$ in compliance with the legislation. Structural corrective measures, training, access to MBP and POP have led to improvements in handler hygiene practices. It is concluded that the project actions made it possible to adapt the institution to the GMP, promoted the interaction teaching, research and extension, since academic learning can be exchanged with the community.
\end{abstract}

Keywords: Good manufacturing practices. Food handlers. Pre-school.

\footnotetext{
${ }^{1}$ Acadêmica do curso de Nutrição da Universidade Federal de Viçosa - UFV, Viçosa - MG, Brasil.

${ }^{2}$ Economista Doméstica, Técnica de Nível Superior do Departamento de Nutrição e Saúde da Universidade Federal de Viçosa - UFV, orientadora do estudo. Av PH Rolfs, s/n. Campus UFV, Viçosa - MG, Brasil.

${ }^{3}$ Mestranda em Economia Doméstica do Departamento de Economia Doméstica da Universidade Federal de Viçosa - UFV, Viçosa - MG, Brasil.

${ }^{4}$ Acadêmica do curso de Nutrição da Universidade Federal de Viçosa - UFV, Viçosa - MG, Brasil.

${ }^{5}$ Professora do Departamento de Nutrição e Saúde da Universidade Federal de Viçosa - UFV, Viçosa - MG, Brasil.

${ }^{6}$ Professora do Departamento de Nutrição e Saúde da Universidade Federal de Viçosa - UFV, Viçosa -MG, Brasil.
} 


\section{Alimentación segura en guardería filantrópica en el municipio de Viçosa - MG}

Resumen: Los preescolares carecen de mayor atención en el control de higiene, considerando la vulnerabilidad de su sistema inmunológico. El objetivo fue informar el desarrollo de las acciones de extensión utilizadas en el servicio de alimentos de una guardería filantrópica en Viçosa (MG) en relación con las Buenas Prácticas de Manufactura (BPM). Se aplicaron dos listas de verificación GMP antes y después de las intervenciones; plan de acción implementado para mejoras estructurales; Se realizaron talleres de higiene y se prepararon un Manual de buenas prácticas (MBP) y Procedimientos operativos estandarizados (SOP). Después de las intervenciones hubo mejoras en las BPM con un aumento de casi el $20 \%$ en cumplimiento de la legislación. Las medidas correctivas estructurales, la capacitación, el acceso a MBP y POP han llevado a mejoras en las prácticas de higiene de los manipuladores. Se concluye que las acciones del proyecto permitieron adaptar la institución al GMP, promovieron la interacción enseñanza, investigación y extensión, ya que el aprendizaje académico puede intercambiarse con la comunidad.

Palabras clave: Buenas prácticas de manufactura. Manipuladores de alimentos. Preescolar

\section{INTRODUÇÃO}

ADeclaração Universal de Direitos Humanos de 1948 contempla no artigo 25 o Direito Humano à Alimentação Adequada (DHAA) que foi incluído na Constituição Brasileira no ano de 2010, por meio da Emenda Constitucional 64, sendo caracterizado como:

O direito humano à alimentação adequada consiste no acesso físico e econômico de todas as pessoas aos alimentos e aos recursos, como emprego ou terra, para garantir esse acesso de modo contínuo. Esse direito inclui a água e as diversas formas de acesso à água na sua compreensão e realização. Ao afirmar que a alimentação deve ser adequada entende-se que ela seja adequada ao contexto e às condições culturais, sociais, econômicas, climáticas e ecológicas de cada pessoa, etnia, cultura ou grupo social. (BRASIL, 2010).

Para efetivação do DHAAé necessário que se garanta a Segurança Alimentar e Nutricional (SAN). Ao considerar os princípios relacionados à SAN, apoiando-se no que propõem Freitas e Pena (2007), tem-se que, o conceito de segurança alimentar é atribuído à qualidade do alimento produzido, como algo que perpassa pelas condições ambientais apropriadas para sua produção, além da sua responsabilidade como fator gerador de desenvolvimento sustentável e qualidade de vida da população. Assim, seu maior objetivo é a produção e distribuição de alimentos de qualidade. Apesar de ser constitucional, no Brasil, esse direito nem sempre é cumprido, provavelmente, por negligência e/ou falta de conhecimento da população sobre os seus direitos, e os poucos que os conhecem, nem todos detêm informação sobre os procedimentos e instrumentos de exigibilidade e, sobre as instâncias nacionais e internacionais de proteção dos mesmos (NASCIMENTO et al., 2009).

Uma das condições para que o DHAA seja garantido é a qualidade higienicossanitária das refeições servidas em creches e escolas em função de sua contribuição para a promoção de uma alimentação adequada e segura. No entanto, muitas instituições não produzem suas refeições em acordo com as Boas Práticas de Fabricação (BPF) de alimentos, o que pode favorecer a multiplicação de micro-organismos, sejam eles patogênicos ou não, comprometendo, assim, a qualidade do alimento e a saúde dos consumidores (OLIVEIRA et al., 2008;

ANSELMO et al., 2015). 
As BPF consistem em práticas de higiene que devem ser seguidas pelos manipuladores de alimentos, desde a escolha e compra dos produtos a serem utilizados no preparo do alimento até a sua chegada ao consumidor final. Assim, as BPF têm como objetivo evitar a ocorrência de doenças provocadas pelo consumo de alimentos contaminados (BRASIL, 2004).

Dados do Sistema de Informação de Agravos de Notificação (SINAN) revelaram que, entre os anos de 2007 e 2016, ocorreram 118.104 casos de Doenças de Origem Alimentar (DOA). Destes, 7.053 ocorreram em crianças com faixa etária de 1 a 4 anos e 7,9\% dos casos foram relatados em creches e escolas (BRASIL, 2016). Diante disso, observa-se a vulnerabilidade do público infantil perante a falta de controle na qualidade higienicossanitária dos alimentos. É importante ressaltar que, nesta faixa etária, o organismo é muito mais vulnerável devido à imaturidade do sistema imunológico, carecendo, assim, de mais atenção.

Diante disso, trabalhos que se propõem a adequar as BPF tem um papel importante na garantia dos pressupostos da SAN. Portanto, considera-se que os estabelecimentos que trabalham com o fornecimento de alimentação coletiva, sejam eles de grande, médio ou pequeno porte; comerciais ou não; restaurantes ou referentes à alimentação de crianças, devem seguir rigorosamente as normas higiênico-sanitárias estabelecidas pelas resoluções vigentes da legislação sanitária, das quais se destacam as Resoluções da Diretoria Colegiada (RDC) no 275/2002 e no 216/2004 (BRASIL, 2002; 2004), a fim de garantir a saúde dos consumidores.

\section{OBJETIVOS}

Relatar o desenvolvimento das ações extensionistas realizadas em uma Unidade de Alimentação e Nutrição (UAN), integrante de uma creche filantrópica de Viçosa (MG), com vistas a adequá-la às Boas Práticas de Fabricação (BPF).

Permitir a divulgação da vivência, interação e troca de experiências dos estudantes com a comunidade.

\section{METODOLOGIA}

Este trabalho foi vinculado ao projeto de extensão Crescendo com Saúde: Alimentação Saudável e Segura no Município de Viçosa-MG, da Universidade Federal de Viçosa (UFV), com o número de inscrição no RAEX: PRJ-178/2017 vinculado ao Programa Crescendo com Saúde (PRG-012/2019). Abaixo foram elencadas as ações realizadas na instituição.

\section{Seleção da Instituição Filantrópica}

No mês de fevereiro de 2017, a responsável pela instituição procurou a coordenadora do Projeto Crescendo com Saúde porque necessitava acatar às exigências da Vigilância Sanitária (VISA) do Município de Viçosa, 
adequando o serviço de alimentação e as práticas dos funcionários às Boas Práticas de Fabricação (BPF). A creche possuía um trabalho filantrópico, ou seja, sem fins lucrativos e estava localizada em Viçosa, Minas Gerais, e atendia ao público de pré-escolares, com a faixa etária entre 1 a 3 anos e 11 meses.

\section{Sujeitos da ação}

O trabalho na instituição filantrópica foi desenvolvido entre os meses de março a dezembro de 2017. A creche possuía, além das crianças, um quadro de funcionários composto por uma diretora pedagógica, três professores, três auxiliares de sala, uma faxineira, uma cozinheira e não contava com nutricionista.

Em relação ao perfil dos membros da equipe da Universidade Federal de Viçosa (UFV) envolvidos na ação extensionista, o trabalho contou com a participação de duas voluntárias, estudantes de graduação do $4^{\circ}$ período e $6^{\circ}$ período do Departamento de Nutrição e Saúde (DNS) e duas estagiárias do curso de Economia Doméstica do $8^{\circ}$ período da graduação. A responsável por orientar as ações era a coordenadora, Economista Doméstica e Técnica de Nível Superior da UFV. As ações também contaram com a participação de duas professoras do DNS as quais auxiliaram na realização das intervenções, supervisionando os conteúdos explorados e realizando visitas de supervisão.

\section{Avaliação das práticas operacionais, edificação e montagem}

A avaliação das práticas operacionais, da edificação e montagem foi feita durante o mês de março de 2017, por meio de uma Lista de Verificação (LV) das BPF, baseada no Anexo II da Resolução - RDC nº 275/2002 (BRASIL, 2002) e uma lista adaptada pelos autores desta resolução, intitulada: Lista de Verificação Detalhada ( $L V D)$. $\mathrm{Na} L V$ os requisitos exigidos para cada item são agrupados em bloco, enquanto na $L V D$ esses requisitos foram separados de forma a serem avaliados individualmente. O objetivo desta adaptação foi possibilitar a identificação mais pontual das inadequações e facilitar suas correções. A fim de classificar a instituição os itens avaliados nas listas foram divididos em doze tópicos.

1) Edificação, Instalações;

2) Equipamentos, Móveis e Utensílios;

3) Higienização de Instalações, Equipamentos e Utensílios;

4) Controle Integrado de Vetores e Pragas Urbanas;

5) Abastecimento de Água;

6) Manejo de Resíduos; Manipuladores;

7) Matérias-primas, Ingredientes e Embalagens;

8) Preparação do Alimento;

9) Armazenamento e Transporte do Alimento Preparado;

10) Exposição ao Consumo do Alimento Preparado; 
11) Controle de Qualidade do Alimento Preparado;

12) Documentação e registro.

As duas listas classificaram as instituições analisadas em grupos de acordo com o seu percentual de adequação: Grupo 1 - 76 a 100\% de atendimento dos itens; Grupo 2 - 51 a 75\% de atendimento dos itens; Grupo 3 - 0 a $50 \%$ de atendimento dos itens.

A aplicação da Lista de Verificação foi realizada antes de iniciar as atividades propostas na instituição filantrópica e após o término das atividades. O objetivo da aplicação destes instrumentos foi verificar a evolução do estabelecimento em relação às exigências da legislação às BPF (BRASIL, 2002; BRASIL, 2004).

\section{Elaboração do plano de ação}

Elaborou-se uma planilha a fim de realizar um planejamento de ações baseado nos resultados da primeira aplicação da $L V$ e $L V D$ e em atendimento ao Relatório de Inspeção emitido pela Vigilância Sanitária do município de Viçosa - MG. O plano de ação foi estruturado no mês de abril de 2017 com base nos Pontos Críticos de Controle em relação à edificação, instalações, móveis, equipamentos e utensílios da entidade. As condições financeiras do estabelecimento foram consideradas, principalmente no que se referia a mudanças estruturais, priorizando-se os pequenos reparos e adaptações urgentes. Dessa forma, seguindo as normas da Agência Nacional de Vigilância Sanitária (ANVISA), foram propostas mudanças no que se refere a estrutura física e fluxo de trabalho da instituição.

O plano de ação foi amplamente discutido com os funcionários e coordenadores da Creche em 4 encontros com duração de aproximadamente $1 \mathrm{~h}$. Nestas reuniões houve troca de experiência entre a equipe do projeto e os membros da instituição, levando-se em consideração os seus anseios, possibilidades, expectativas e necessidades.

\section{Adequação da estrutura física}

As medidas tomadas para corrigir as inadequações da estrutura física às BPF na UAN da instituição filantrópica foram executadas entre os meses de maio a novembro de 2017 e foram realizadas a partir do plano de ação supracitado que atendeu às exigências das legislações brasileira (BRASIL, 2002; 2004).

\section{Capacitações}

Foram ministradas capacitações com base nas exigências da RDC 216/2004 (BRASIL, 2004), abordando os seguintes temas: Doenças veiculadas por alimentos; Contaminação de alimentos; Boas Práticas na Aquisição, Recepção e Armazenamento de Matérias-Primas; Boas Práticas em Higiene Pessoal; Boas Práticas na Preparação e Distribuição dos Alimentos; Boas Práticas na Higienização dos Equipamentos, Móveis, Utensílios e Ambiente; 
Controle de Vetores e Pragas Urbanas; Controle da Qualidade da Água; Manejo de Resíduos; Materiais e Produtos para Higienização.

Os temas citados acima foram divididos em três capacitações. Essa foi uma forma de não cansar os participantes, considerando que foram realizados em um intervalo considerável de tempo, com intuito de não haver sobrecarga de informações e nem mesmo esquecimento do que foi tratado nos treinamentos anteriores.

A capacitação sobre higiene pessoal foi a primeira a ser realizada e aconteceu no dia 25 de agosto de 2017. Apresentou-se conteúdos ilustrativos do uniforme ideal do manipulador de alimentos, os exames periódicos de saúde que devem ser feitos, os perigos dos micro-organismos quando entram em contato com os alimentos e os procedimentos corretos de higienização das mãos.

No dia 29 de setembro de 2017 realizou-se a segunda capacitação, sobre higiene dos alimentos, esta aconteceu em dois momentos, uma parte teórica e outra prática. No primeiro momento apresentou-se os cuidados exigidos desde a recepção até a distribuição final do alimento, os tipos de contaminação que podem acontecer com os mesmos e como evitá-las. No segundo momento aconteceu a parte prática, em que na cozinha da creche, realizou-se o processo de higienização segura de um vegetal, como preconiza a ANVISA, seguida de sua sanitização.

A terceira capacitação foi sobre a Higiene Ambiental, e ocorreu no dia 17 de novembro de 2017, e funcionou nos mesmos parâmetros da anterior. Na parte teórica, foram apresentadas imagens sobre como deve ser a higiene do ambiente de produção (cozinha), a importância de limpar o ambiente e em seguida desinfetá-lo (álcool $70 \%$ ou solução clorada). Assim, foi entregue às participantes um folder com as orientações de como realizar a limpeza de cada ambiente como teto, bancada, paredes e ambientes em geral, a fim de que consultassem em caso de qualquer dúvida. Na parte prática, demonstrou-se a desinfecção, por meio do uso de solução clorada, da pia da cozinha para que pudessem visualizar na prática a higienização correta do ambiente

Ministrou-se todos os conteúdos das capacitações por meio de metodologias ativas de ensino e aprendizagem com a conjugação de diversos procedimentos e instrumentos didáticos, a saber: Expositiva Dialogada, Debate, Demonstrações Práticas, Dinâmica de Grupo, Apresentação de Material previamente elaborado entre outras. Foram utilizadas lista de presença e registros fotográficos para evidenciar e arquivar a participação e atividades teóricas e práticas realizadas durante as oficinas.

A avaliação do aprendizado foi realizada no final das três capacitações, na forma de Quiz que foi projetado no PowerPoint. Os participantes receberam duas tarjetas de cores diferentes, sendo a verde para as respostas consideradas verdadeiras e a vermelha para as falsas.

\section{Educação continuada}

A educação continuada foi desenvolvida nos ambientes de trabalho da entidade, junto aos colaboradores e coordenadores, semanalmente, por cerca de $4 \mathrm{~h}$, entre os meses de agosto a novembro de 2017. Teve como 
finalidade fixar os conhecimentos adquiridos nos cursos de capacitação, além de monitorar se as atividades estavam sendo realizadas de forma correta, sempre respeitando as opiniões dos colaboradores e as condições físicas e financeira da instituição.

Esta ação foi realizada por meio do monitoramento das atividades realizadas pelos funcionários em relação à BPF na manipulação de alimentos. Quando necessário, foram executadas demonstrações práticas de como as atividades deveriam ser desenvolvidas para assegurar as BPF. A ação foi avaliada a partir da observação das mudanças de atitudes dos funcionários em relação às instruções repassadas.

\section{Elaboração do Manual de Boas Práticas}

O Manual de Boas Práticas (MBP) foi um documento elaborado nos meses de setembro, outubro e novembro de 2017. O MBPé uma exigência da Vigilância Sanitária para orientar e contribuir para a garantia da produção de alimentos seguros em serviços de alimentação. Ele deve ser específico para cada estabelecimento. Para sua construção foi utilizado o modelo disponibilizado pelo Conselho Regional de Nutricionista - $4^{\text {a }}$ Região (CRN-4) intitulado "Guia para Elaboração do MBP para Manipulação de Alimentos” (KRAEMER, SADDY, 2007).

A elaboração do MBP levou em conta a realidade econômica da instituição e a observação detalhada das atividades desenvolvidas pelo estabelecimento, valorizando a contribuição do conhecimento da equipe. Abordou os requisitos mínimos exigidos e explicitados na legislação brasileira (BRASIL, 2002; 2004). Foram incluídos no MBP: caracterização minuciosa das instalações; manutenção e higienização das instalações, dos equipamentos e dos utensílios; controle da água de abastecimento, controle integrado de vetores e pragas urbanas; capacitação profissional; controle da higiene e saúde dos manipuladores, manejo de resíduos; boas práticas em higiene pessoal; boas práticas na compra, recepção, armazenamento, preparo e distribuição dos alimentos e controle e garantia de qualidade do alimento preparado.

\section{Elaboração de Procedimentos Operacionais Padronizados (POP)}

Os POP foram elaborados entre os meses de outubro e novembro de 2017 em atendimento às resoluções - RDC n$^{\circ} 275$, de 21 de outubro de 2002 e RDC n² 216, de 15 de setembro de 2004 (BRASIL, 2002; 2004). Os itens trabalhados nos POP foram: higienização das instalações, equipamentos e utensílios; controle da potabilidade da água; higiene e saúde dos manipuladores (lavagem das mãos); manejo de resíduos; controle integrado de vetores e pragas urbanas; seleção de matérias-primas, ingredientes e embalagens; programa de recolhimento de alimentos.

\section{RESULTADOS E DISCUSSÃO}

As diretrizes da Política Nacional de Extensão Universitária, Interação Dialógica, Interdisciplinaridade e Interprofissionalidade, Indissociabilidade Ensino-Pesquisa-Extensão, Impacto na Formação do Estudante, e 
Impacto e Transformação Social (FORPROEX, 2012), nortearam as ações deste estudo. Assim, a extensão universitária é uma forma de interação entre a universidade e a comunidade na qual está inserida permitindo troca de conhecimentos, cultura e valores.

Neste contexto, este projeto promoveu a integração de estudantes, professores e técnicos com pais/ responsáveis, crianças e funcionários das instituições filantrópicas de Viçosa, MG. A utilização de metodologias ativas propiciou a participação efetiva da comunidade, sendo importante para ampliação do público atendido por meio da educação continuada. Promoveu ainda, aos estudantes de graduação em Nutrição e Economia Doméstica a oportunidade de aplicar os conhecimentos adquiridos em sala de aula e ao mesmo tempo aprender com as vivências dos funcionários.

Durante a realização de todas as ações do projeto foi necessário que o estudante apresentasse um conjunto de habilidades cognitivas, sociais e profissionais adquiridas no curso de graduação em Nutrição e Economia Doméstica para que conseguissem realizar uma abordagem assertiva na comunidade. Os conhecimentos gerados nas disciplinas ministradas pela UFV foram imprescindíveis para a realização das ações do projeto.

Acredita-se que este tipo de projeto traga transformações sociais eficazes e inúmeros benefícios aos indivíduos das Instituições filantrópicas no que tange ao atendimento ao DHAA. O projeto propôs mudanças nas condutas de higiene e estruturais que objetivaram à obtenção de uma alimentação mais saudável e segura impactando na saúde pública.

Ressalta-se que o projeto atendeu a política de extensão do Departamento de Nutrição e Saúde, na área de Alimentos e ao Plano Nacional de Extensão Universitária, priorizando parcerias importantes com profissionais da Economia Doméstica/Serviço Social e com entidades não governamentais do município, a fim de facilitar o diálogo com a comunidade, a troca de saberes e a integração do conhecimento.

A seguir são apresentados os resultados das ações que procuraram atender as diretrizes da Política Nacional de Extensão:

\section{Avaliação das práticas operacionais, edificação e montagem}

A Creche Filantrópica selecionada foi bastante receptiva às mudanças, o que contribuiu diretamente para o desenvolvimento das ações, influenciando assim, nos resultados positivos encontrados. Esta afirmativa pode ser evidenciada pela melhoria dos percentuais de adequação às Boas Práticas de Fabricação (BPF) da creche (Figura 1 e 2).

Os resultados das avaliações realizadas antes das intervenções na creche revelaram que os itens Documentação e registro e Controle de qualidade do alimento preparado foram os que obtiveram o menor percentual de adequação, enquanto Controle integrado de vetores e pragas urbanas, Abastecimento de água, e Exposição ao consumo do alimento preparado apresentaram o maior índice de adequação em ambas as listas (Figura 1 e 2). 

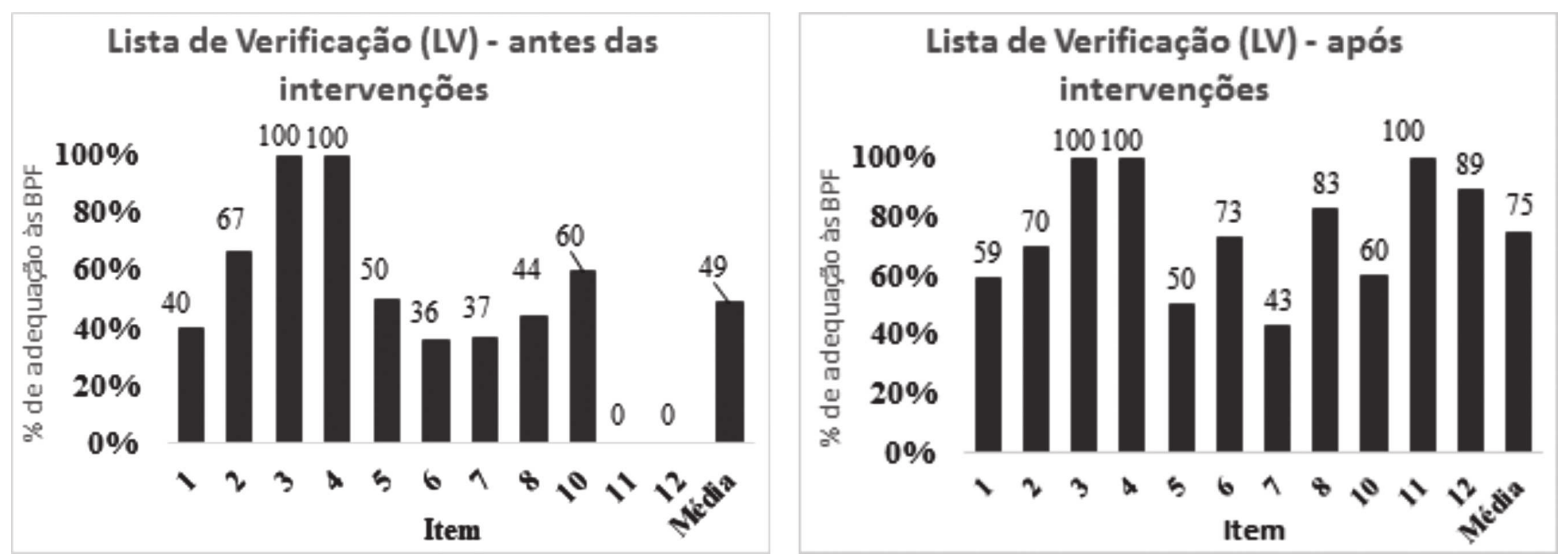

Figura 1 - Percentual de adequação às Boas Práticas de Fabricação de acordo com a Lista de Verificação $(L V)$ da RDC n ${ }^{\circ}$ 275/2002 antes e após as intervenções em Instituição Filantrópica de Viçosa (MG).

Legenda: Item 1 - Edificação, instalações, equipamentos, móveis e utensílios; Item 2 - Higienização de instalações, equipamentos e utensílios; Item 3 - Controle integrado de vetores e pragas urbanas; Item 4 - Abastecimento de água; Item 5 - Manejo de resíduos; Item 6 - Manipuladores; Item 7 - Matérias-primas, ingredientes e embalagens; Item 8 - Preparação do alimento; Item 9 - Armazenamento e transporte do alimento preparado (Este item não consta nos gráficos, pois não se aplica às atividades realizadas pela instituição analisada neste trabalho); Item 10 - Exposição ao consumo do alimento preparado; Item 11 - Controle de qualidade do alimento preparado; Item 12 - Documentação e registro.
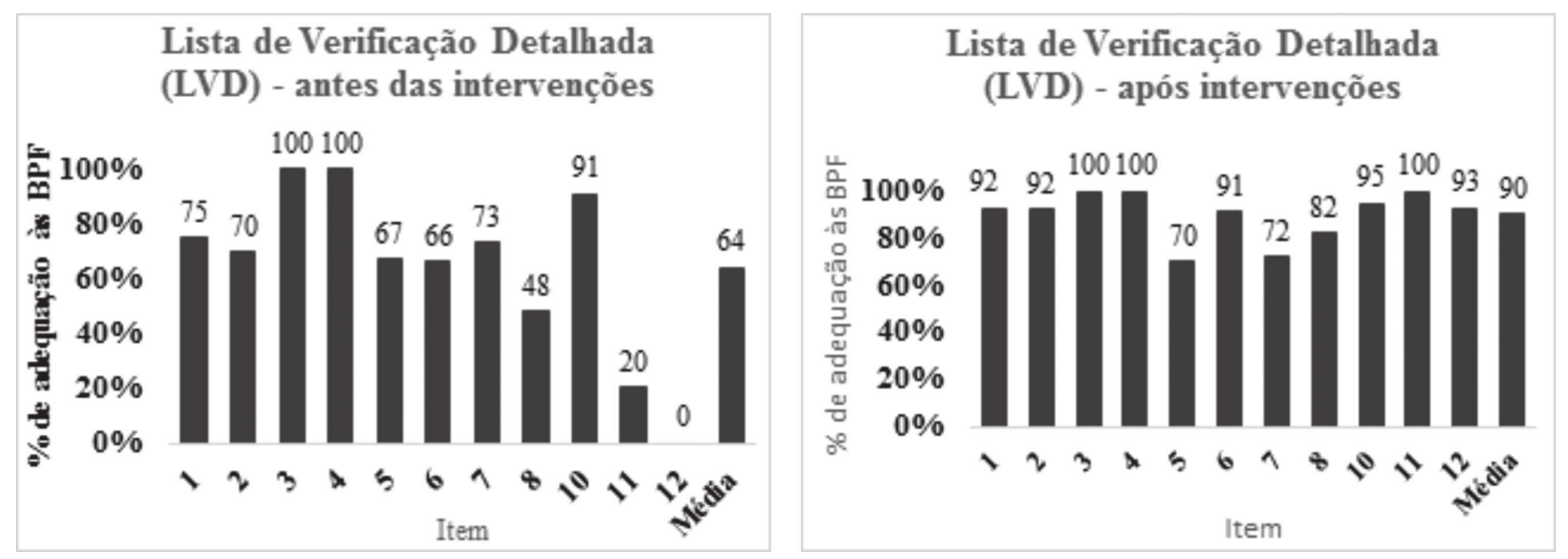

Figura 2 - Percentual de adequação às Boas Práticas de Fabricação de Instituição Filantrópica de Viçosa (MG) de acordo com a Lista de Verificação Detalhada (LVD), antes e após as intervenções.

Legenda: Item 1 - Edificação, instalações, equipamentos, móveis e utensílios; Item 2 - Higienização de instalações, equipamentos e utensílios; Item 3 - Controle integrado de vetores e pragas urbanas; Item 4 - Abastecimento de água; Item 5 - Manejo de resíduos; Item 6 - Manipuladores; Item 7 - Matérias-primas, ingredientes e embalagens; Item 8 - Preparação do alimento; Item 9 - Armazenamento e transporte do alimento preparado (Este item não consta nos gráficos, pois não se aplica às atividades realizadas pela instituição analisada neste trabalho); Item 10 - Exposição ao consumo do alimento preparado; Item 11 - Controle de qualidade do alimento preparado; Item 12 - Documentação e registro.

Diferente destes resultados, Correio et al. (2018) demonstraram que o item Manipuladores foi o que apresentou o menor percentual de adequação $(35,7 \%)$, no entanto, relataram que as condições higienicossanitárias estavam satisfatórias em escolas municipais da região urbana de Visconde do Rio Branco-MG.

Observou-se que antes das intervenções a creche classificava-se no Grupo 2 que abrange $51 \%$ a $75 \%$ de atendimento aos itens (BRASIL, 2002) com 68\% de adequação pela Lista de Verificação Detalhada (LVD) e $54 \%$ pela Lista de Verificação $(L V)$. Após as intervenções houve uma melhoria expressiva na classificação da 
creche. A instituição atendeu a $86 \%$ de adequação dos itens pela $L V D$ e $73 \%$ pela $L V$, passando, portanto, a pertencer ao grupo 1. Oliveira et al. (2017) encontraram resultados semelhantes em unidades de alimentação de escolas públicas municipais. Constataram que $54 \%$ dos itens verificados apresentaram-se em conformidade com a regulamentação de BPF, classificando-a no Grupo 2. Em estudo que avaliou seis escolas públicas de Caxias MA, observou-se que as escolas apresentaram índices de não conformidade variando de $34,17 \%$ a $14,2 \%$, ou seja, todas classificadas no Grupo 3.

\section{Elaboração do plano de ação}

O plano de ação foi elaborado a partir do levantamento dos Pontos Críticos de Controle (PCC) da Creche. Para cada PCC identificado foram elaboradas propostas de medidas corretivas e estabelecidas as datas para execução da correção. A proposta consistiu-se em adequar a creche às exigências das RDC nº 275 e 216 (BRASIL, 2002, 2004). O plano de ação contemplou adequações na edificação, instalações, móveis, equipamentos e utensílios e levou em conta as condições financeiras da instituição. Enfocou, prioritariamente, pequenos reparos e adaptações urgentes. O plano foi discutido com a coordenadora e com os manipuladores de alimentos a fim de garantir o diálogo e a participação destes na tomada de decisão, considerando as necessidades físicas dos ambientes.

\section{Capacitações}

Capacitações sobre higiene pessoal, higiene do ambiente e higiene dos alimentos foram ministradas em três encontros com duração de 1 h30 cada. Participaram das capacitações em média cinco (5) pessoas envolvidas com a produção das refeições. Os temas abordados foram doenças veiculadas por alimentos, higiene pessoal, higiene dos alimentos e higiene do ambiente.

Como resultado da avaliação realizada a partir do Quiz aplicado após as capacitações, obteve-se que $100 \%$ das questões levantadas foram respondidas corretamente.

Os principais resultados alcançados na instituição filantrópica após as capacitações estiveram relacionados ao aumento da consciência e das práticas de higiene dos envolvidos em relação às BPF. Destacam-se entre eles: mudanças comportamentais, melhorias na organização da unidade de alimentação da creche, procedimentos corretos de lavagem das mãos e melhorias nas práticas de higiene pessoal, do ambiente e dos alimentos. Em estudo que avaliou o impacto da capacitação em BPF para manipuladores de alimentos, os resultados revelaram repercussão positiva no nível de conhecimento dos manipuladores, demonstrando a importância do aperfeiçoamento constante, para garantir a qualificação profissional dos manipuladores e a produção de refeições seguras do ponto de vista higienicossanitário (DEVIDES et al., 2014).

De acordo com Osaili et al. (2011) para que a capacitação dos envolvidos com a alimentação seja eficazé preciso abranger informações sobre o controle de temperatura dos alimentos, práticas adequadas de preparação 
de alimentos, prevenção de contaminação cruzada, procedimentos adequados de limpeza e descarte, agentes causadores de doenças transmitidas por alimentos, grupos de alto risco e outros fatores que contribuem para a transmissão de doenças por alimentos contaminados e estratégias de prevenção. Neste estudo todos esses tópicos foram abordados nas capacitações e durante a educação continuada. De acordo com Sultana et al. (2013) falhas nos procedimentos de higiene pessoal, ambiental ou dos alimentos provocadas pelos manipuladores podem incorrer em risco de contaminação dos alimentos. Esta pode ocorrer por meio do acondicionamento dos produtos em temperatura inadequada, da ocorrência de contaminação cruzada, dentre outros fatores que favorecem a multiplicação de micro-organismos patogênicos e, consequentemente, compromete a saúde dos consumidores.

Vale salientar, que nas capacitações utilizou-se metodologias ativas de ensino e aprendizagem com a conjugação de procedimentos e instrumentos didáticos como: expositiva dialogada, debate, demonstrações práticas, apresentação de material previamente elaborado entre outras. Os manipuladores de alimentos, os voluntários e a coordenadora da creche participaram das atividades ativamente com perguntas e sugestões. Esta atividade proporcionou momentos de interação e troca de saberes entre os funcionários e a equipe do projeto. Destaca-se o potencial de metodologias ativas de ensino e aprendizagem na formação de futuros profissionais de nutrição no sentido de torná-los aptos a, efetivamente, promover a alimentação saudável e segura para a população como uma primeira das justificativas deste projeto. As metodologias ativas recorrem a procedimentos didáticos dinâmicos e interativos que estimulam a exteriorização de ideias. Argumenta-se que estas metodologias contribuem para o pensamento crítico e reflexivo que, por sua vez, qualifica a ação política e promove a autonomia dos sujeitos (VILLAS BOAS, 2005). As metodologias ativas permitem que indivíduos ou coletividade atuem como sujeitos do processo, aptos a definir temas e problemas a serem resolvidos prioritariamente, uma vez que, leva em consideração aquilo que eles já conhecem.

\section{Adequações na estrutura física}

A estrutura física da UAN da creche foi modificada atendendo o Relatório de inspeção da Vigilância Sanitária do município de Viçosa - MG e os resultados da aplicação das Listas de Verificação. Dentre as adequações realizadas, destacam-se:

- Substituição do ventilador por um exaustor;

- Instalação de um depurador;

- Retirada de objetos estranhos como cadeiras de madeira e telefone do interior da área de produção;

- Substituição da geladeira;

- Instalação de uma pia exclusiva para higienização das mãos;

- Separação de uma pia para lavagem de utensílios e outra para lavagem de vegetais;

- Construção de um passa-pratos;

- Instalação de tela em uma porta que conecta a cozinha ao salão de refeições;

- Criação de um setor para a devolução de pratos sujos; 
- Instalação de separação física entre os setores de pré-preparo de alimentos (carnes, vegetais/grãos e higienização de utensílios);

- Uso de uniforme padronizado (jaleco e calça branca) pelos manipuladores de alimentos;

- Pintura do teto com tinta lavável;

- Colocação de uma porta de correr com tela;

- Substituição das lâmpadas para melhorar a iluminação;

- Instalação de luminárias com proteção antiquedas;

- Substituição da lixeira por outra com acionamento via pedal, com tampas e devidamente identificada.

Estudos que avaliaram a adequação da estrutura física em UAN institucionais revelaram deficiências na edificação, estrutura física, instalações, conservação das áreas externa e interna dos estabelecimentos e controle de qualidade da água de abastecimento entre outros (CARDOSO, SOUZA, SANTOS, 2005; PEREIRA et al., 2015). Esses achados demonstram a importância deste estudo, uma vez que se propõe a adequar a estrutura física de UAN.

\section{Educação continuada nos locais de trabalho}

As ações de educação continuada foram realizadas na creche, semanalmente, e duravam cerca de $4 \mathrm{~h}$ cada. Esta ação envolvia as mesmas pessoas envolvidas nas capacitações e possibilitou que estes continuassem a ser instruídos quanto à adoção correta das BPF, além de permitir que as dúvidas fossem sanadas. Os temas abordados foram os mesmos trabalhados nas capacitações, no entanto, as dúvidas mais recorrentes foram relacionadas ao cronograma de higienização do ambiente e às planilhas de registros de procedimentos da UAN.

Como resultado desta ação obteve-se uma maior consolidação dos conhecimentos percebida pelas mudanças de atitudes dos manipuladores e demais funcionários em relação à adoção das BPF.

A Política Nacional de Extensão Universitária preconiza o desenvolvimento de ações que utilizem a educação continuada, visando a participação da população não somente como meros expectadores, mas também como sujeitos ativos no processo educativo (FORPROEX, 2012). Portanto, procurou-se atender a essa premissa nas atividades de educação continuada da creche. Foi preocupação constante da equipe, repassar os conhecimentos adquiridos na universidade, considerando os conhecimentos prévios da população assistida, instigando-a a participar efetivamente do trabalho realizado, dessa forma, o aprendizado é mútuo. Por meio da extensão, pode-se proceder à comunicação, socialização e democratização do conhecimento existente, bem como das novas descobertas para a comunidade. As atividades de extensão deste projeto também propiciaram a complementação da formação adquirida nas atividades de ensino, com a aplicação prática.

\section{Elaboração do Manual de Boas Práticas}

O Manual de Boas Práticas (MBP) foi elaborado exclusivamente para a creche participante do projeto e foi alocado em local de fácil acesso dentro da Unidade de Alimentação e Nutrição (UAN). O instrumento está 
sendo usado para consulta dos manipuladores de alimentos e coordenadores, a fim de auxiliá-los em possíveis dúvidas com relação às BPF. Este instrumento torna-se imprescindível uma vez que a UAN não possui um nutricionista para acompanhamento das atividades. Observou-se que o MBP teve uma boa aceitação pelos manipuladores.

Para construção do MBP os estudantes envolvidos no Projeto também tiveram a oportunidade de realizar um treinamento na utilização on-line do instrumento: Ferramentas para as Boas Práticas na Alimentação Escolar disponibilizado pelo Centros Colaboradores de Alimentação e Nutrição do Escolar (CECANE) que auxilia na elaboração do MBP. De acordo com o Guia de instrução das Ferramentas para as Boas Práticas na Alimentação Escolar esse instrumento serve como:

\begin{abstract}
Apoio para os nutricionistas que auxiliam na avaliação das práticas aplicadas e indicam, a partir de uma classificação por grau de risco higienicossanitário, as melhorias necessárias para a garantia de alimentos mais seguros. A partir da aplicação de um instrumento harmonizado, permite aos gestores municipais e estaduais a identificar problemas comuns e definir prioridades de intervenção com base no risco higienicossanitário. Na esfera nacional, possibilita a construção de um mapa do risco higienicossanitário das escolas brasileiras, importante subsídio para a avaliação e aprimoramento das políticas públicas. (CECANE, 2013, p.3).
\end{abstract}

\title{
Elaboração de Procedimentos Operacionais Padronizados (POP)
}

Foram elaborados os seguintes POP: higienização das instalações, equipamentos e utensílios; controle da potabilidade da água; higiene e saúde dos manipuladores (higienização das mãos); manejo de resíduos; controle integrado de vetores e pragas urbanas; seleção de matérias-primas, ingredientes e embalagens; programa de recolhimento de alimentos e higienização de toalhas. Os POP foram anexados ao MBP e foram impressos em tamanho maior para serem afixados em local visível na UAN.

\section{CONCLUSÕES}

Conclui-se que as ações desenvolvidas na creche filantrópica contribuíram para adequar a instituição às BPF, o que foi comprovado pela melhoria na classificação da creche em ambas as listas de verificação.

Observou-se ainda que a aplicação das medidas corretivas acarretou melhorias nas práticas operacionais, edificação e montagem e a adequação da estrutura física da UAN. Além disso, as capacitações sobre higiene, a utilização e o acesso ao MBP e aos POP propiciaram avanços nas práticas de higiene dos manipuladores de alimentos.

Este projeto promoveu a interação ensino, pesquisa e extensão, a partir do momento em que as informações adquiridas ao longo da graduação e aprimoradas por meio das pesquisas foram transmitidas à comunidade, além de possibilitar o levantamento de novos dados que servirão de subsídios para a produção de mais pesquisas. Ao mesmo tempo, os estudantes e demais membros do projeto aprofundaram seus conhecimentos por meio de 
situações práticas vivenciadas na comunidade.

Espera-se que as ações possam ser ampliadas para outras instituições filantrópicas em função de suas características sociais, carência de recursos financeiros para contratar serviços especializados nesta área e classe social do público atendido.

\section{FONTES DE FINANCIAMENTO}

O projeto contou com uma bolsa do Programa Institucional de Bolsas de Iniciação à Extensão Universitária - PIBEX/UFV para uma estudante.

\section{REFERÊNCIAS}

ANSELMO, D. B.; WERLE, C. H.; HOFFMANN, F. L. Ocorrência de Escherichia coli e Staphylococcus aureus resistentes a antimicrobianos e parasitos Entamoeba coli e Ascaris lumbricoides em merendas escolares. Revista do Instituto Adolfo Lutz, São Paulo, v. 74, n. 4, p. 399-405, 2015. Disponível em: <http:/ /www.ial.sp.gov.br/resources/insituto-adolfo-lutz/publicacoes/rial/10/rial74_4_completa/artigos-separados/ 1674.pdf>. Acesso em: 12 ago. 2018.

BRASIL. Emenda Constitucional $n^{o}$ 64, de 4 de fevereiro de 2010. Altera o art. $6^{\circ}$ da Constituição Federal, para introduzir a alimentação como direito social. Brasília, DF: Presidência da República, 2010. Disponível em: <http://www.planalto.gov.br/ccivil_03/constituicao/emendas/emc/emc64.htm>. Acesso em: $17 \operatorname{dez} 2019$.

BRASIL. Ministério da Saúde. Agência Nacional de Vigilância Sanitária - ANVISA. Resolução RDC n ○275 de 21 de outubro de 2002. Dispõe sobre o Regulamento técnico de procedimentos operacionais padronizados aplicados aos estabelecimentos produtores /industrializadores de alimentos e a Lista de verificação das boas práticas de fabricação nesses estabelecimentos. Diário Oficial da União: seção 1, Brasília, DF, n. 206, p. 126, 23 out. 2002. Disponível em: <www.anvisa.gov.br>. Acesso em: 16 mai 2018.

BRASIL. Ministério da Saúde. Agência Nacional de Vigilância Sanitária - ANVISA. Resolução RDC nº 216, de 15 de setembro de 2004. Regulamento Técnico de Boas Práticas para Serviços de Alimentação. Diário Oficial da União; Poder Executivo. Brasília, DF, 16 set 2004. Disponível em: < www.anvisa.gov.br>. Acesso em: 16 mai. 2018.

BRASIL. Vigilância epidemiológica das doenças transmitidas por alimentos no Brasil. 2016. Disponível em: <http://portalarquivos.saude.gov.br/images/pdf/2016/junho/08/Apresenta-o-Surtos-DTA-2016.pdf >. Acesso em: 19 set. 2018.

CARDOSO, R. C. V.; SOUZA, E. V. A.; SANTOS, P. Q. Unidades de alimentação e nutrição nos campi da Universidade Federal da Bahia: um estudo sob a perspectiva do alimento seguro. Revista de Nutrição, Campinas, v. 18, n. 5, p. 669-680, Oct. 2005. Disponível em: <http://www.scielo.br/ scielo.php?script=sci_arttext\&pid=S1415-52732005000500010\&lng=en\&nrm=iso $>$. Acesso em: $17 \mathrm{dez}$. 2019. http://dx.doi.org/10.1590/S1415-52732005000500010. 
CECANE - Centros Colaboradores em Alimentação e Nutrição do Escolar. Guia de Instruções das Ferramentas para as Boas Práticas na Alimentação Escolar. 2013. Disponível em: <http://www.ufrgs.br/cecane/ downloads/>. Acesso em: 19 set. 2018.

CORREIO L. S. B.; CORREIO V. G. L.; FONSECA C. S.; CORREIO M. P. S. Verificação das Boas Práticas de Fabricação (BPF) nas cantinas de Escolas Públicas de Visconde do Rio Branco. Revista UniScientiae | UNIVIÇOSA. v. 1, n. 1, p. 41-53 jan./jun. 2018.

DEVIDES, G. G. G.; MAFFEI, D. F.; C., MORTATTI, M. P. L. Perfil socioeconômico e profissional de manipuladores de alimentos e o impacto positivo de um curso de capacitação em Boas Práticas de Fabricação. Brazilian Journal of Food Technology, Campinas, v. 17, n. 2, p. 166-176, Jun. 2014. Disponível em: <http://www.scielo.br/scielo.php?script=sci_arttext\&pid=S1981-67232014000200009\&lng=en\&nrm=iso>. Acesso em: 17 dez. 2019. http://dx.doi.org/10.1590/bjft.2014.014.

FREITAS, M. C. S.; PENA, P. G. L. Segurança alimentar e nutricional: a produção do conhecimento com ênfase nos aspectos da cultura. Revista de Nutrição, Campinas, v. 20, n. 1, p. 69-81, Fev. 2007. Disponível em: <http://www.scielo.br/scielo.php?script=sci_arttext\&pid=S1415-

$52732007000100008 \& \operatorname{lng}=\mathrm{en} \& \mathrm{nrm}=\mathrm{iso}>$. Acesso em: $12 \mathrm{dez} .2019$.

\section{FORPROEX - FÓRUM DE PRÓ-REITORES DE EXTENSÃO DAS UNIVERSIDADES PÚBLICAS BRASILEIRAS. XXXI ENCONTRO NACIONAL DO FORPROEX. Carta de Manaus. Maio de 2012.}

KRAEMER, F.B.; SADDY. M.A. Guia de elaboração do manual de boas práticas para manipulação de alimentos. Rio de Janeiro: Conselho Regional de Nutricionistas - $4^{a}$ Região, 2007, 52p. Disponível em: <http:// www.crn4.org.br/cms/upl/arqs/guia-de-elaboracao-do-manual-de-boas-praticas-para-manipulacao-dealimentos.pdf >. Acesso em: 20 dez. 2019.

NASCIMENTO, R.C.; BOCCHI, C.P.; RECINE, E.; LEÃO, M.; BEGHIN, N.; MALUF, R.; BURITY, T.F.V.; SCHOLZ, V. Avanços e Desafios da Implementação do Direito Humano àAlimentação Adequada no Brasil. Relatório Técnico. Brasília. Rio de Janeiro:ABRANDH-CERESAN-CONSEA-FAO-RLC-ALCSH; 2009. Disponível em: <http://www.sesc.com.br/mesabrasil/doc/Avan\%C3\%A7os-e-desafios.pdf>. Acesso em: 17 dez. 2019.

OLIVEIRA, M.N.; BRASIL, A.L.D.; TADDEI, J.A.A.C. Avaliação das condições higiênico-sanitárias das cozinhas de creches públicas e filantrópicas. Ciência \& Saúde Coletiva, v. 13, n. 3, p. 1051-1060, 2008. Disponível em: <http://www.scielo.br/scielo.php?script=sci_arttext\&pid=S1413-81232008000300028>. Acesso em: $11 \mathrm{dez} .2019$.

OLIVEIRA, A. S. S. S; SOARES, E. L. P; MACEDO, J. L, PEREIRA, I. C; GOMES, F. O; ASSUNÇÃO, M. J. S. M. Condições higiênico-sanitárias em unidades de alimentação de escolas públicas. Revista Ciência e Saberes, v. 3, n. 3, p. 585-593, 2017.

OSAILI, T.M.; OBEIDAT, B.A; JAMOUS D.O.A; BAWADI, H.A. Food safety knowledge and practices among college female students in north of Jordan. Food Control, v. 22, n. 2, p. 269-276, 2011.

PEREIRA, F. G. et al. Condições higiênicas de um serviço de alimentação em um centro de atenção psicossocial. Revista de Ciência Tecnologista, Posadas, n. 23, p. 48-53, 2015. Disponível em: <http:// www.scielo.org.ar/scielo.php?script=sci_arttext\&pid=S1851-75872015000100008\&lng=es\&nrm=iso>. Acesso em: 17 dez. 2019. 
ULTANA, A.; AWAN, A.; TEHSEEN, I. Sanitation Practices Among Food Handlers Working in Street Restaurants in Rawalpindi, Pakistan. Rawal Medical Journal, Pakistan, v. 38, n. 4, p. 425-427, 2013.

VILLAS BOAS, B. M. F. O portfólio no Curso de Pedagogia: ampliando o diálogo entre professor e aluno. Educação e Sociedade, v. 26, n.90, p. 291-306, 2005.

Submetido em: 30/10/2018. Aceito em: 19/11/2019. 